\title{
Brittle cornea syndrome
}

INSERM

\section{Source}

INSERM. (1999). Orphanet: an online rare disease and orphan drug data base. Brittle cornea syndrome. ORPHA:90354

Brittle cornea syndrome is a form of Ehlers-Danlos syndrome characterized by a severe ocular manifestations due to extreme corneal thinning and fragility with rupture in the absence of significant trauma, and progression to blindness. Extraocular manifestations comprise deafness, developmental hip dysplasia, and joint hypermobility. 